\title{
Computational Models Developed for the Corrosion of
}

\section{Prestressing Steel}

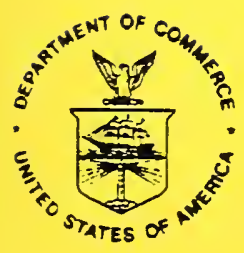

U.S. Department of Commerce

Robert A. Mosbacher, Secretary

National Institute of Standards and Technology

John W. Lyons, Director

Building and Fire Research Laboratory

Gaithersburg, MD 20899 



\section{Computational Models Developed for the Corrosion of}

Prestressing Steel

\section{Spencer T. Wu*}

James R. Clifton

\section{*Bolling Air Force Base}

Air Force Office of Scientific Research

Washington, DC 20332

March 1991

U.S. Department of Commerce

Robert A. Mosbacher, Secretary

National Institute of Standards and Technology

John W. Lyons, Direcior

Building and Fire Research Laboratory

Gaithersburg, MD 20899 



\section{Abstract}

Stress corrosion cracking and general corrosion are the two major processes potentially responsible for corrosion failures in prestressed concrete. Modeling for the purpose of estimating the corrosion rates of steel in prestressed concrete are discussed in the paper. For steel in concrete, localized corrosion processes are not well understood. It is premature at present to develop a sophisticated but still incomplete mathematical model. Instead, a simplified approach is proposed for the quantitative evaluation of corrosion rates. A model was developed based upon considerations of diffusion processes and electrochemical reactions. The dominant chemical factors, such as the concentration of oxygen at the electrodes, are treated as primary variables in the differential equations.

Two approaches which have been frequently used to treat stress corrosion cracking are briefly described. The first approach is based on a conventional engineering approach by estimating the stress intensity factors under various environments. In the second approach, the surface energy at grain boundaries is estimated along the crack path. It is suggested that the chemical potentials and concentrations of the important absorbed species be included in the energy expression.

Keywords: concrete; fracture energy; fracture mechanics; general corrosion; modeling; prestressing steel; stress corrosion cracking. 


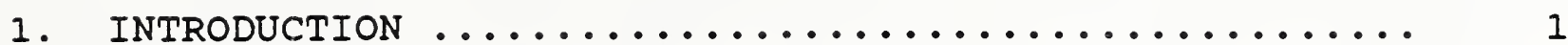

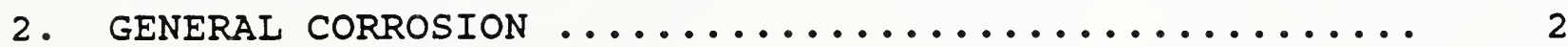

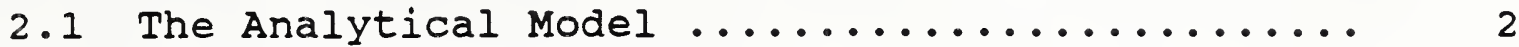

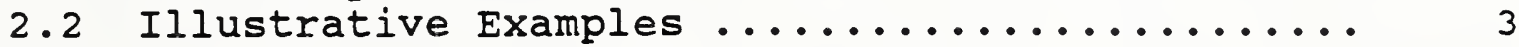

3. STRESS CORROSION CRACKING .................... 4

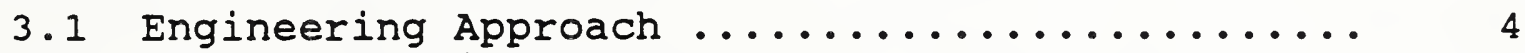

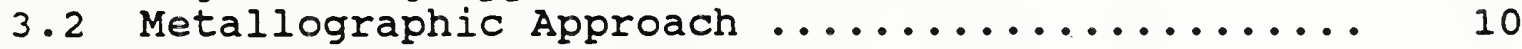

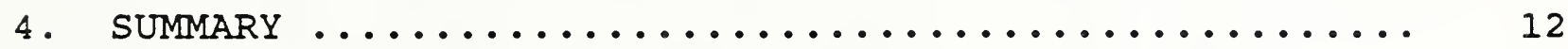

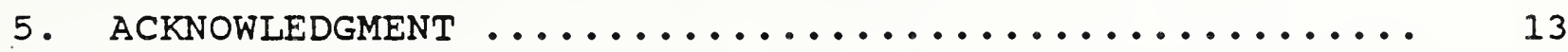

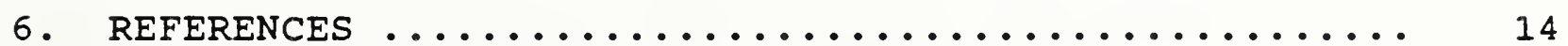

\section{List of Figures}

Figure 1. Corrosion Rates vs. Time. Curve $e$ is based on equation 5. Curves $b-1, b-2$, and $b-3$ are based on equation 3 using respective values for a of $0.1,0.2$ and 0.5 . Reference values for cases $b$ and $e$ are taken $a t t=0$ and $t=1$

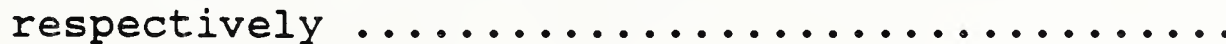

Figure 2. Schematic of Stress Corrosion Crack ......... 8

Figure 3. Fracture time, $t_{R}$, as a function of stress intensity factor, $K_{i c}$. Comparison of results obtained in $0.6 \mathrm{M} \mathrm{NaCl}$ and in gaseous hydrogen for Si-Cr-MC (45 SCD 6). The arrow indicates that there was no fracture. (Charbonnier and

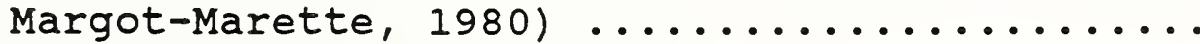

\section{List of Table}

Table 1. Solutions of $U_{j}$ from Equation 3 Based on Simple

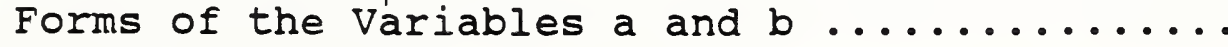





\section{Introduction}

The corrosion of steel in prestressed concrete (PC) may cause a potential threat to the integrity of the structure or pipeline of which it is a part even though the concrete in PC is generally of high quality (Treadway, 1971; Szilard, 1969). The major problems in assessing the threat have been identified as the lack of methods for estimating the corrosion rates and for evaluating the effects due to stress corrosion (e.g., Galligo and Climent (1980); Wu and Clifton, 1981). Because of the complex processes involved in the corrosion of steel in concrete, an ad hoc approach was proposed in reference no. 4 for computing the rates of general corrosion processes. Ordinary differential equations, with time as the independent variable, were suggested to be used in making the computations. This paper extends the previous effort. A few simple parametric functions are assumed for illustration and solutions are plotted and discussed.

For stress corrosion cracking, the most direct treatment of stress corrosion failures appears to be the estimation of the fracture stresses in terms of the environmental and geometric parameters. Semi-empirical formulas based on limited experimental tests are traditionally used by engineers. A brief description of this engineering approach is given in this paper. The work-energy concept proposed by cottrell (1964) appears to provide a more fundamental approach that can correlate failure mechanisms with materials properties, i.e., the microstructural properties. This type of microstructure approach is also described in the paper. It is suggested that the expression for the surface energy include the chemical potentials of the important absorbed species at the grain boundaries of the prestressing steel. 


\section{General corrosion}

\subsection{The Analytical Model}

Diffusion and electrochemical reactions are the major processes involved in the corrosion of steel. Due to the complicated conditions existing near the electrodes, it was proposed (Wu and Clifton, 1981) to use the following simplified equations in evaluating the rates for general corrosion:

$$
\begin{aligned}
& \frac{d U_{0}}{d t}=D_{0} \frac{U_{0}^{*}-U_{0}}{A_{1}^{2}}+C_{1}\left(\Delta \phi, U_{0}\right)+C_{2}\left(U_{c 1}\right) \\
& \frac{d U_{f}}{d t}=D_{f} \frac{U_{f}^{*}-U_{f}}{A_{2}^{2}}+C_{3}\left(\Delta \phi, U_{0}\right)+C_{4}\left(U_{c 1}\right)
\end{aligned}
$$

Where $U_{0}, U_{f}$, and $U_{c l}$ represents the concentrations of oxygen, ferrous and ferric ions, and chloride ions, respectively, near the electrodes, and $\Delta \phi$ is a term representing the potential difference between electrodes. The terms $U_{0}^{*}$ and $U_{f}^{*}$ denote the concentrations of oxygen and of ferrous and ferric ions, respectively, at the boundaries of ionic and hydrate layers surrounding the prestressing steel. $D_{0}$ is the equivalent diffusivity of oxygen. $D_{f}$ represents the diffusivity of ferrous and ferric ions near corrosion sites on the prestressing steel. The parameters $A_{1}$ and $A_{2}$ link the thickness of effective ionic and hydrate layers around the corrosion sites. The variables $C_{1}$, $c_{2}, c_{3}$ and $c_{4}$ are functions to be determined from the experimental data. In an exact analytical representation, the ferrous and ferric ions should be considered separately. In the approximate representation given by equation (2) their concentrations are combined.

The forms of the above equations are the same. They may be expressed as:

$$
\frac{d U_{i}}{d t}+a U_{i}=a U_{i}^{*}+b
$$

with $U_{i}$ representing the variables $U_{0}$ or $U_{f}$ in equations (1) and (2), and $a$ and $b$ representing the rest of the variables. 


\subsection{Illustrative Examples}

A few simple parameters functions are assumed for $a$ and $b$ as listed in table 1. The general solution for equation (3) for these cases is:

$$
U_{i}=k_{1}(b)+K_{2}(b) e^{-a t}
$$

where $\mathrm{k}_{1}$ (b) and $\mathrm{k}_{2}$ (b) are dependent on the boundary conditions. The corresponding solutions of $k_{1}$ and $k_{2}$ for the assumed functions are also listed in table 1. To illustrate the shapes of the transient states, solutions of $U_{i}$ for case $b$ in table 1 are plotted in figure 1. The curves $b-1, b-2$, and $b-3$ represent solutions for $U_{i}$ when the value of variable a is chosen to be $0.1,0.2$, and 0.5 , respectively.

\subsection{Discussion}

The shapes of the transient states from solving equation (3) are compared with those from the traditional approach used in the field of electrochemistry, i.e., characterization of the reactions with a set of partial differential equations and solving the equations using conventional techniques such as the Laplace Transform method. If the reaction is of the simple charge transfer type; the corrosion current can be expressed as (e.g., Fraunhofer and Banks, 1972):

$$
i(t)=s \frac{1}{\sqrt{t}}
$$

where $S$ is a coefficient that represents the effect from the significant parameters and is independent of time. The form of $i(t) / S$ is shown as curve $e$ in figure 1 to give a comparison with the solutions obtained from equation (3). The limiting states for all these solutions approach zero. 


\section{Stress Corrosion Cracking}

Traditionally, the macroscopic approach to evaluation of the fracture has been emphasized. Descriptions of the use of this engineering approach to evaluate the stress corrosion cracking of prestressing steel are given in the following section. The correlation between the fracture stress and microscopic material properties is likely to lead to a more realistic solution to the problem. Cottrell's (1964) microscopic model based on

dislocations theory has the most general theoretical background. A description of this approach is given in a later section. In the case that the specific mechanism is known, e.g., due to film rupture or hydrogen embrittlement (Pugh, 1977), the prediction of failure by a mathematical modeling approach is simplified.

\subsection{Engineering Approach}

The most direct way of determining the fracture stress is probably by representing the stress intensity factor $\left(k_{1}\right)$ by the initial crack geometries. For plates, $k_{1}$ has been conveniently expressed in terms of the ratio of the crack length $a_{1}$ to the width $w$ of the specimen (Chu and colleagues, 1980):

$$
K_{I}=F\left(\frac{a_{1}}{w}\right)
$$

The function of $F$ depends on the material properties as well as on the geometry. In practice, $F$ is usually represented as a polynominal in terms of the selected variable:

$$
F\left(\frac{a_{1}}{w}\right)=\sum_{j=1}^{N} c_{j}\left(\frac{a_{1}}{w}\right)^{n_{j}}
$$

Where $a_{1}$ is the crack width,

$w$ is the thickness of the plate,

$C_{j}, n_{j}$, are constants, and

$\mathrm{N}$ is the total number of the terms used to represent the function $F$. 


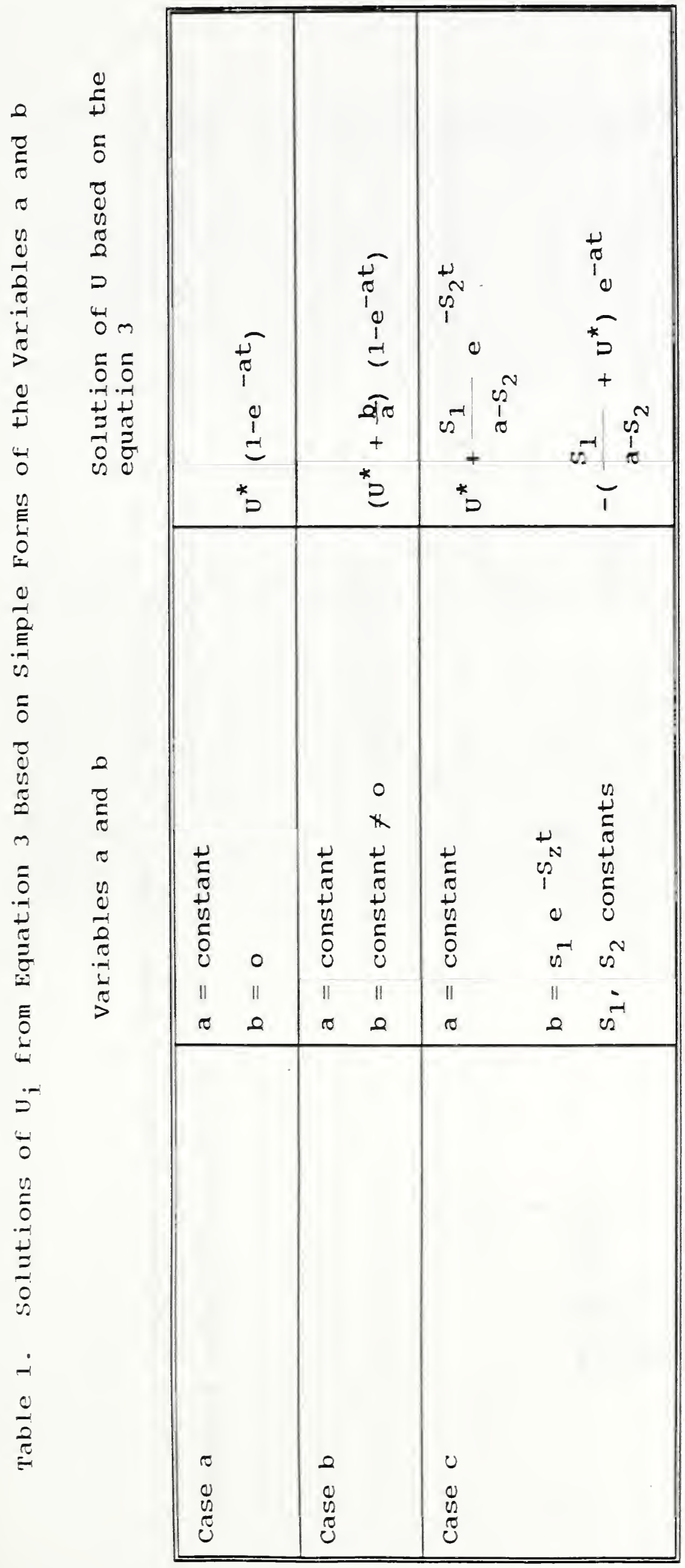




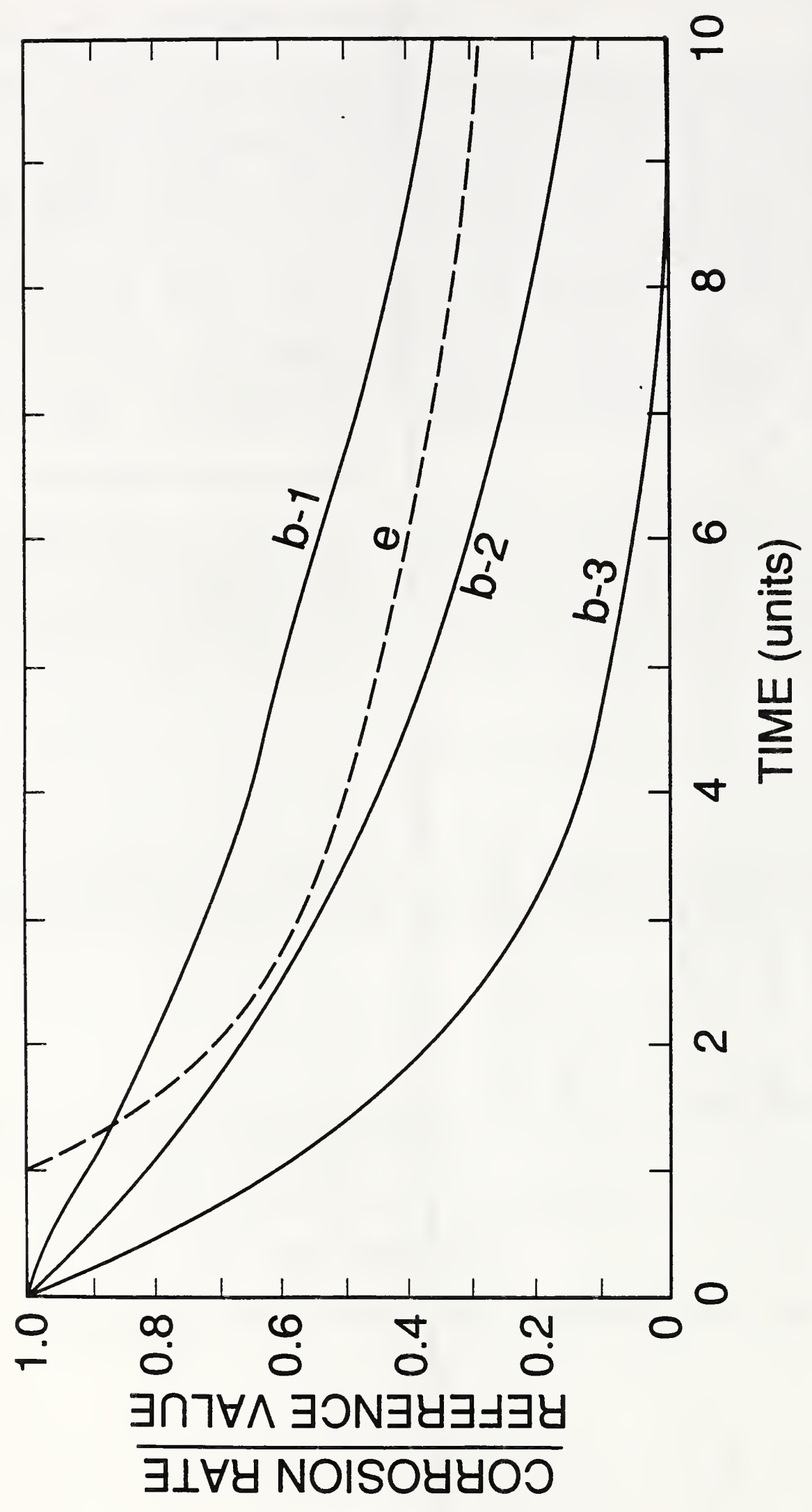

ర్ర

$\overbrace{1}^{-10}$

힉

겅

เ $\mathrm{\alpha} \cdot \mathrm{A}$

u 0

ये ज्ञ

ชิ

ن

$\varepsilon^{\pi} \sigma$

車

-

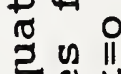

to

व

$0>$

- 0

in $\rightarrow \frac{y}{\pi}$

$0+1$

- 0

on

(1) 过

물

空. 天

อ

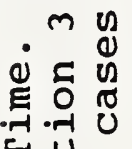

Et

i.

in

n 0

แิ

म0

a os $>$

ᄃ 2

- 0

0

40

넝

i

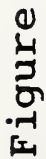


$\mathrm{N}$ was taken as 4 , and $\mathrm{n}_{\mathrm{j}}$ as $1 / 21,3,4$, successfully, in the consideration of stress corrosion cracking of steels in $\mathrm{H}_{2} \mathrm{~S}$ solutions (Chu and colleagues, 1980).

In environments which may assist crack growth, the magnitude of critical stress intensity factor is undoubtedly reduced. The amount of the reduction in terms of the yield strength is usually estimated based on the corroded conditions. With a similar approach, the stress intensity factor $K$ for a prestressing tendon or wire may be expressed by considering pitting conditions. For example, the fracture stress condition of a prestressing rod was expressed as (Galligo and Climent, 1980; Asitz, 1976):

$$
K_{=c}=0 \sqrt{D}\left(\left[-.8554 \frac{a}{D}-0.1642\right] \frac{a}{b}+2.948 \frac{a}{D}+0.3309\right)
$$

where $K_{I C}$ is the critical stress intensity factor 0 is the stress, $D$ is the diameter of the prestressing rod, and $a$ and $b$ define the pit (see figure 2).

In studies of the kinetics of corrosion cracking, the fracture time $\left(t_{R}\right)$ is usually found to be a function of the stress intensity factor. The $t_{R \cdot k}$ curve generally has a different shape with different test media. Two common shapes are shown in figure 3 (Charbonnier and Margot-Marette, 1980) with $t_{R}$ plotted on a logarithmic scale. It is not difficult to find appropriate mathematical expressions to represent these data. A similar approach may be used for the corrosion of prestressing steel. As stated earlier, this engineering approach could be the most direct way of finding the time to failure. 


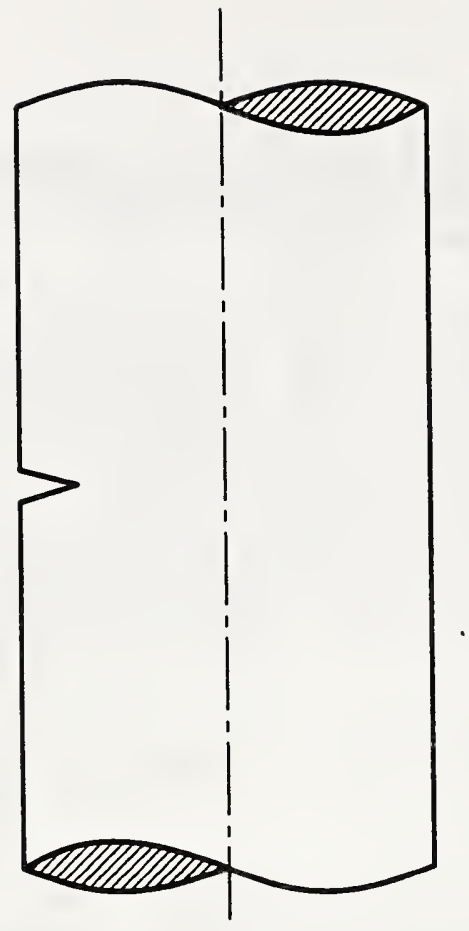

Typical stress corrosion crack

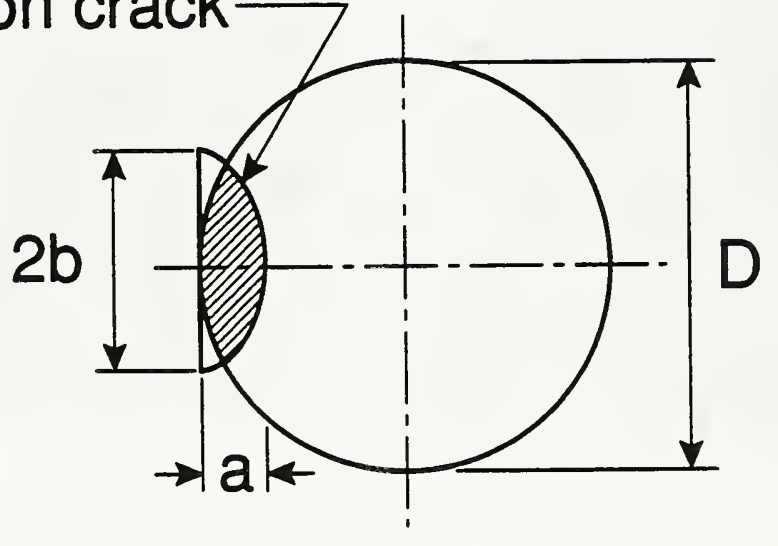

Figure 2. Schematic of stress corrosion Crack. 


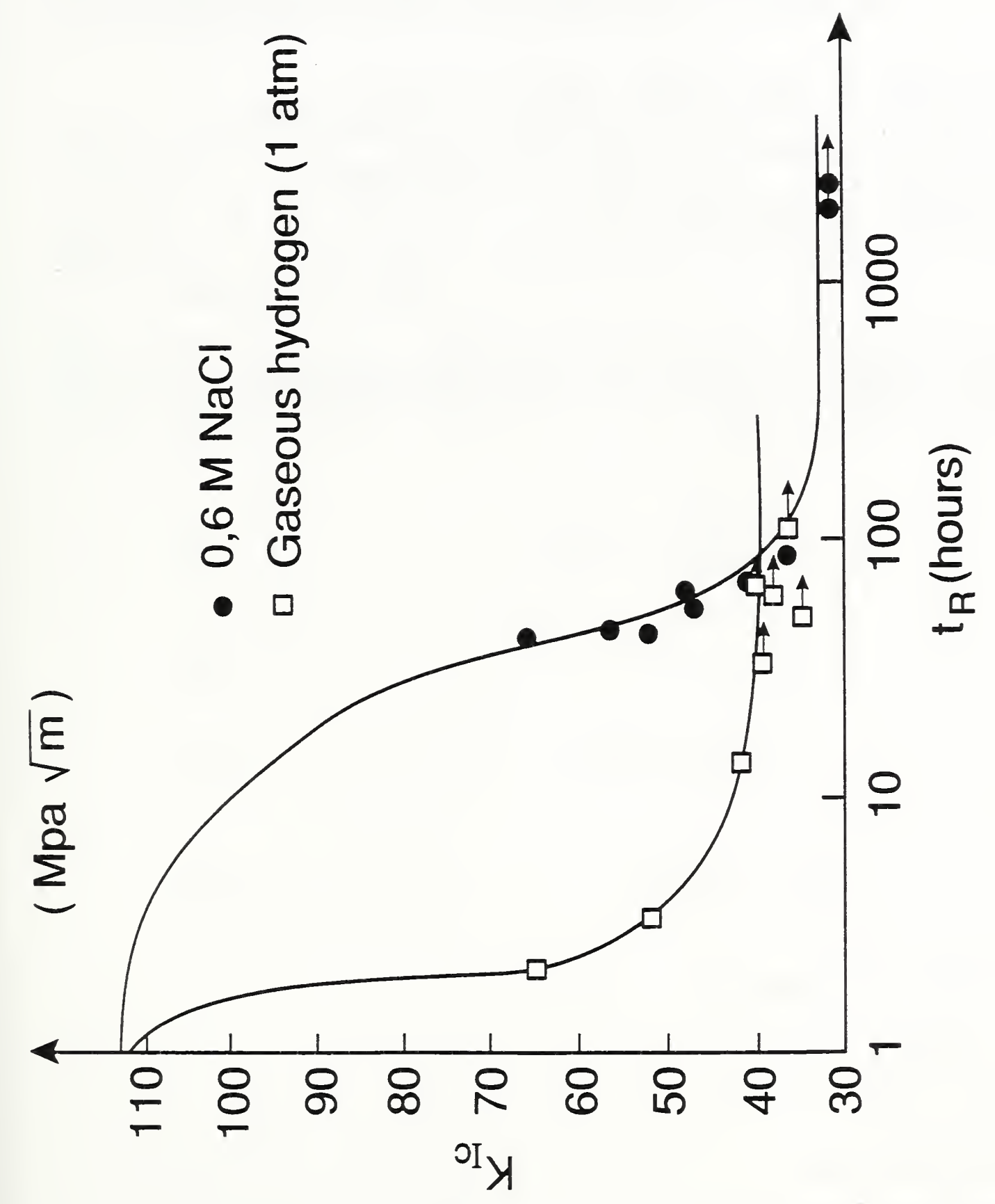




\subsection{Metallographic Approach}

Stress corrosion cracking (SCC) may follow either an

intercrystalline or a transcrystalline path (Logan, 1966). For either type of failure, the fracture energy, $w$, can be expressed by:

$$
w=w_{d}+w_{s}+w_{e}+w_{c}
$$

where

$\mathrm{w}_{\mathrm{d}}$ : energy related to the stress field of the dislocation

$\mathrm{w}_{\mathrm{s}}$ : surface energy of the new cracks in the crystal

$w_{e}$ : elastic energy of the crack

$\mathrm{w}_{\mathrm{c}}$ : work done in increasing the volume on opening up the crack

If the crack growth occurs by coalescence of dislocations in a body-centered cubic crystal, the expressions for the variables are given by cottrell (1964) as:

$$
\begin{gathered}
w_{d}=\frac{G n^{2} a_{a}^{2}}{4 \pi(1-v)} \ln \frac{4 R}{d} \\
w_{s}=2 \gamma d \\
w_{e}=-\frac{\pi(1-v)}{8 G} a_{a}^{2} d^{2} \\
w_{c}=\frac{\sigma n a_{a} d}{2}
\end{gathered}
$$

where $G$ is the modules of rigidity

$\gamma$ is surface energy

$v$ is poisson's ratio

$o$ is the applied stress

$R$ is the effective radius of the stress field 
$d$ is the crack length, and

$a_{a}$ is the lattice constant

$\mathrm{n}$ is the dislocation constant

For the problem considered here, the surface energy term needs to be reformed. The chemical potentials of the important species, such as hydrogen, must be considered at the grain boundary. The following modified Gibb's equation is proposed:

$$
d \tau+\Sigma \mu_{i} d c_{i}+d E_{d}=0
$$

where $\mu_{i}$ represents the chemical potentials for the species considered, and $c_{\text {i }}$ represents the surface concentrations. The variable $d E_{d}$ is introduced to compensate for the discrepancies between the theoretical equation compared to the actual SCC behaviors. The value of $\mathrm{dE}_{\mathrm{d}}$ should be determined directly from the experimental data.

The feasibility of linking equation (11) with those for general corrosion (eqs. (1) and (2)) to mathematically describe the complete SCC process will be determined in future studies. 


\section{Summary}

An analytical model for evaluating the corrosion rates of steel in prestressed concrete is proposed. As a feasibility study, the transient states of the solutions are plotted against the results obtained from a different approach often used in the field of electrochemistry. Both approaches may lead to limiting states as time tends to infinity. For stress corrosion cracking, either the engineering approach or the metallographic approach may be used to estimate the fracture stress of the prestressing steel. For the latter approach, the surface energy is linked with chemical potentials and the concentrations of the important absorbed species at the grain boundaries. The Gibbs equation with a compensating term should serve such a purpose. 


\section{Acknowledgment}

The author wish to acknowledge the helpful discussions with Dr. Geoffrey Frohnsdorff and Dr. Neville Pugh, National Institute of Standards and Technology. The valuable suggestions and information contributed by Mr. Jose Galligo and Dr. Climent, Laboratorio Central de Estructures y Materiales is also appreciated. Support of this work by the U.S.-Spain Joint committee is gratefuliy acknowledged. 
6. References

1. Treadway, K.W.J. (1971). Corrosion of Prestressed Wire in Concrete, Br. Corro. J., 6 , March.

2. Szilard, R. (1969). Corrosion and Corrosion Protection of Tendons in Prestressed Concrete Bridges. J.Amer. Conc. Inst., $\underline{66}, 42-57$.

3. Galligo, J.M. and J. Climent (1980). Factors Affecting the Corrosion of steel in Prestressed Concrete. Central construction Materials Testing Laboratory, spain.

4. Wu, S.T. and J.R. Clifton (1981). Analysis and Modeling of Corrosion of Steel in Prestressed Concrete. National Bureau of Standards NBSIR 81-2390.

5. Cottrell, A.H. (1964). Theory of Crystal Dislocations. Gordon and Breach Science Publishers.

6. Ton Fraunhofer, J.A. and C.H. Banks (1972). Potentiostat and its Applications. Butterworth and Co.

7. Pugh, E.N. (1977). A Post Conference Evaluation of Our Understanding of the Failure Mechanisms, NACE Conference on Stress Corrosion Cracking and Hydrogen Embrittlement of Iron Base Alloys.

8. Chu, W.Y., S. Li, C. Haiao, and J. Tien (1980). Mechanism of Stress corrosion cracking of steels in $\mathrm{H}_{2} \mathrm{~S}$. Corrosion 39, $9,475-482$.

9. Astiz, M.A. (1976). Estudio de la establided de una fisura superficial en un a lambre de acero de alta resistencia. Tesis Doctoral Presentada en la ETSICCD, Madrid.

10. Charbonnier, J.C. and H. Margot-Marette (1980). Comparison of Fracture Test Data for Some High Strength Steels Stressed in a Saline Medium and in Gaseous Hydrogen. Corrosion Science, $\underline{20}, 6,821-834$.

11. Logan, H.L. (1966). The stress Corrosion of Metals. John wiley and Sons. 


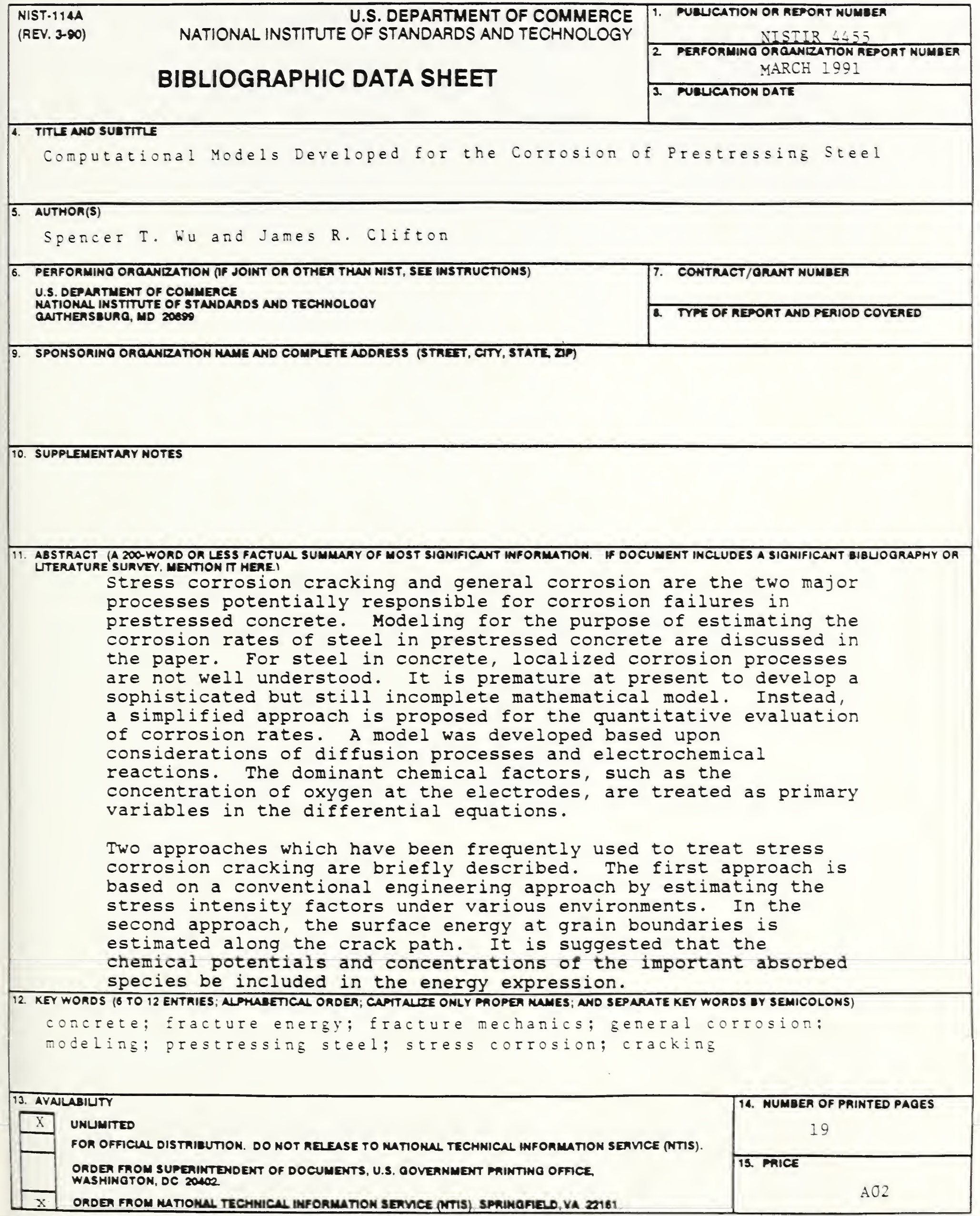




